\title{
Stylish With Outer Wear
}

\author{
Nurul Aini, Hapsari Kusumawardani \\ Departement of Industrial Technology \\ Universitas Negeri Malang \\ Malang, Indonesia \\ nurul.aini.ft@um.ac.id
}

\begin{abstract}
The world of fashion is now growing, emerging fashion trends every year. Fashion trends often return to previous years, so there are some fashions back in the past trend in today, especially for the fashion-clothing that is timeless, such as outer clothing. Outer wear is an outfit or clothing that covers or completes clothing. Outer wear can make the appearance more stylish or help someone to appear confident. Today's outer clothing can be used for various occasions as well as many variations.
\end{abstract}

Key words - stylish; outer wear; fashion; trend

\section{INTRODUCTION}

Fashion is always changing, the definition implies that fashion is about change, and that an object, style, or activity stands out against a backdrop of stability[5]. Outerwear including timeless or fashion clothing that is not wobbled by time, or clothing that can be worn all the time. Thus timeless fashion models will always appear in accordance with the development of fashion trends. Trend mode consists of two word trends and modes. Trend comes from the English language which means following the latest model, according to the dictionary mode is the latest variety of ways or the latest form at a certain time. Thus fashion trends can be interpreted as the latest model of interest to the community. Line of development have generally been considered the main organizing paradigms of trends in fashion [11]. Similar opinion is mentioned that the trend of fashion is defined as a way or style of dress that always follow the times, which from time to time there is always renewal in terms of shape, color, variations caused by the progress of Science and Technology [6]. As well as outerwear developments occur in both design, color and fabric. there is a mention that stylist evolution of the outerwear icon [3]. This years, outerwear into fashion trends in Indonesia, especially among Muslim women, because one function of outerwear is covering the curve of the wearer's body. Deviantri [2] mention other than as a supporting appearance, outerwear or outfit can be used to warm the body when the cold weather. For Muslim women outfit can help cover body shape.

As mentioned above, outerwear can cover and complement the outfit, then outerwear can be said multifunction, so its benefits are many, one of them will make someone look stylish, and this will increase one's confidence.

\section{A. Outerwear}

Some definitions of outerwear are, according to The Randon House Dictionary [1] outerwear is clothing worn over other clothes, especially for the outdoors. This shows that outerwear is a garment worn over other clothing, especially for outdoors. Outerwear is clothing worn outdoors or clothing designed to be worn outside other garments, as opposed to underwear [10]. Meaning outerwear is an outfit worn outdoors or clothes that are designed to be worn outside other clothes, as opposed to underwear. According to Webster merrriem [8] outer is clothing for outdoor wear or as opposed to underwear. By definition this outerwear is clothing for outerwear or as opposed to underwear. Of the three terms of the outerwear, it can be concluded that aouterwear is a garment worn on top of another cloth, and used to go out of the house or the opposite of underwear. outerwear can be made from a variety of textile fabrics but not transparent. Kambata et.all. [4] said that in the market the major materials fpr men's suit and women's outer garment are woll, cotton, silk, and polyester facbric.

In principle, outerwear, is clothing worn outside the main outfit or outfits, and can be used for winter or to cover or get around the underwear that is less supportive of appearance, can also be used to look stylish. This is in accordance with the opinion .. which states With a little research and a little investment, it is not too big a challenge to find some great styles of outerwear that will not let you down when the winter winds come calling. The above statement shows abhwa with outer wear can still be stylish even in winter. Similar opinion is mentioned that outerwear into a fashion trend that is preferred by teenagers and mothers, using outer wear such as vests, blazers, cardigans etc. Will add more beautiful appearance and stylist [9].

\section{B. Types Of Outerwear}

Below will describe some types of outerwear outfit or clothing worn outside the main clothing, which can be used as a reference for the selection of outer clothing:

\section{1) Vest}

Vest or commonly called a vest and usually sleeveless. The material can consist of jeans, parasites, wool, knit etc. Vest can be used for formal and non-formal activities. Vest for formal events is usually mixed with a plain shirt that looks neat and professional. Vest of jeans and knit materials can be used for non-formal activities, for example, combined with t- 
shirts. Vest made of leather or parasite can be worn during the winter.

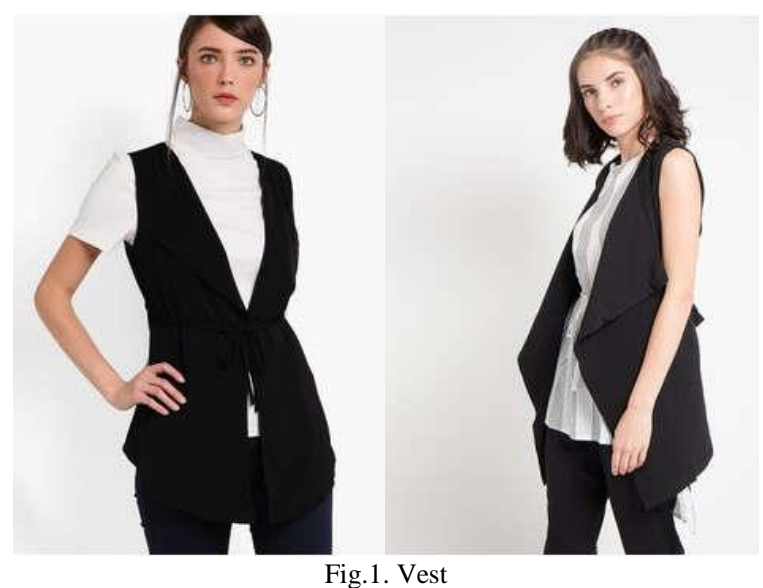

\section{2) Cardigan}

Long cardigan is an easy outer in mix and match, because pattern and model and motif are various, like flowers, stripes, polka dot etc. Cardigan gives the impression warm also look stylish, and can cover the chest or large arms so as not to look too big and more covered.

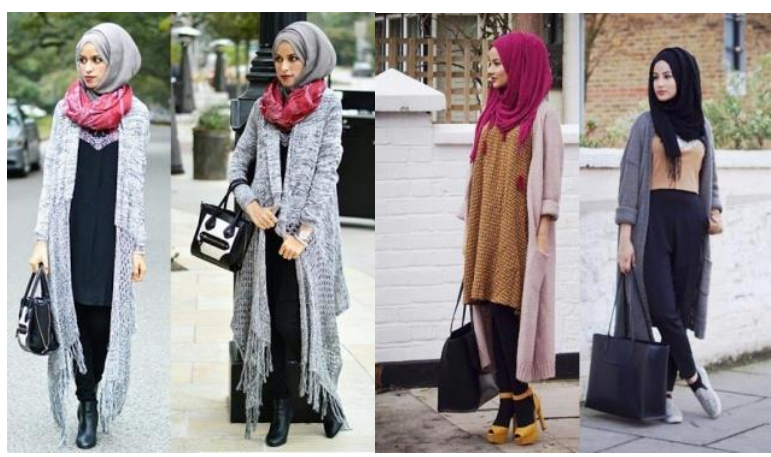

Fig. 2. Long Cardigan

\section{3) Sweater}

Sweater works warm and add confidence. Sweater easy to use or easy to use and remove it. Sweater material is usually made of wool or knit or from thick t-shirts. Called sweaters because they are designed to absorb sweat, sweaters are also often referred to as pullover, jumper or jersey.

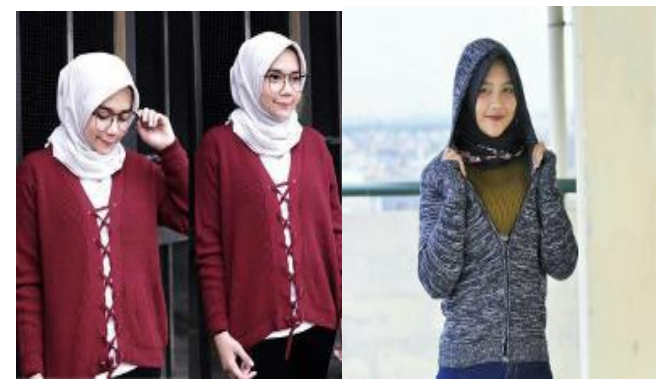

Fig.3. Sweater

\section{4) Hoodie}

This hoodie is generally made of thickness and there are creatures or head coverings as a complement, so it can be used to cover the head from heat, cold, or rain. Hoodie can mix and match with jeans, skirt, spandex pants etc. Hoodie is basically a sweater with a hat. Generally designed with a front pocket and rope to adjust the hat. Hoodies can be opened up front with buttons or zipper. Outer hoodie comes from the development of formal clothing of Catholic priests in medieval times. Hoodie is commonly used for jogging and sight seeing.

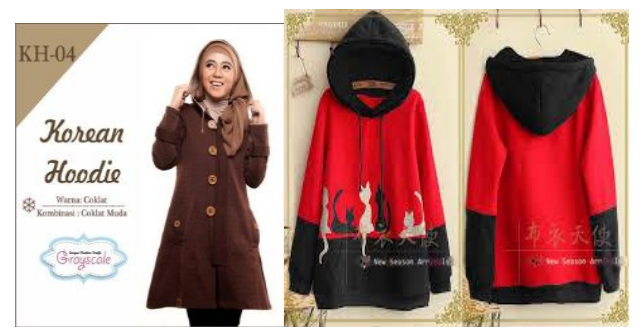

Fig.4. Hoodie

\section{5) Jacket}

Jacket including outer outfit that length up to waist or hips, used to withstand wind and cold weather. The jacket opening is located at the front of the neck down, to open it usually using retsluiting or buttons. Jackets are made of thick fabrics and are often dressed in upholstery and inner heating materials such as bird feathers or goose feathers. Most jackets are also made of materials that can not be washed. The coat belongs to the jacket type but the length exceeds the pelvis.
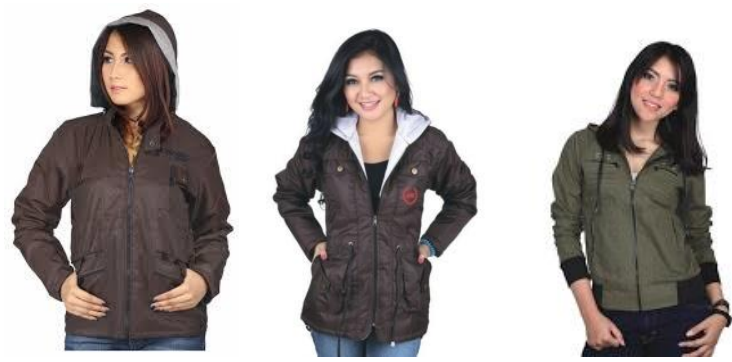

Fig. 5. Jacket

\section{6) Parka}

Parka is inspired by the army's outfit with a distinctive feature on the front of the box pocket. Parka including outer clothing, and intended to warm the body, so it is appropriate for the streets or when riding a motorcycle. 


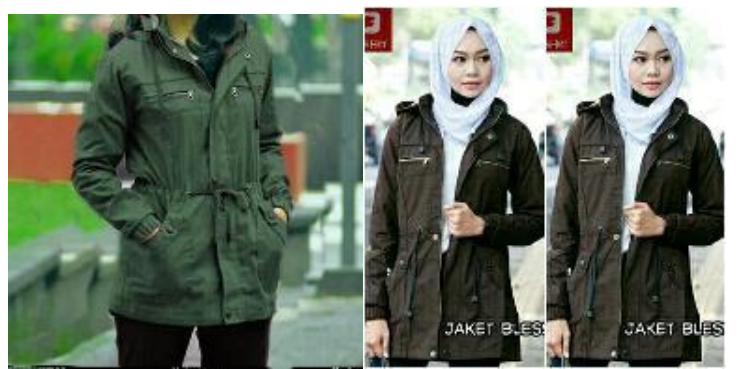

Figure 6 Parka

\section{METHODS}

The method used in making this article is conceptual. Conceptual or nonpenelitian article are the author thoughts on an issue, as outlined in written form by first reviewing sources relevant to the problem. Opinions or establishment writers are the most vital part in the article. Principal elements contained in article conceptual namely; title, author name, abstract and keyword, introduction, discussion, conclusion, and reference.

Various theories show that outer clothing can add confidence and make the wearing more stylish. Thus, outer wear is multifunctional, it is very interesting to discuss.

\section{RESULTS AND DISCUSSIONS}

In this article more emphasized on the outer outfit type of cardigan that will give the impression of style on the wearer, especially long cardigan in women who wear Muslim dress. Cardigans are usually buttoned in front, with the development of the changing mode, so many cardigans that do not use the front button or just use the rope as a binder. The original goal of cardigan is one type of clothing supporters are intended to anticipate the cold and also prevent and protect the appearance of the main clothing itself. Furthermore, cardigan is now a fashion trend complementary fashion. In other words, long cardigan as outer clothing is a fashion that can support the appearance of someone to be more confident. The same thing says that cardigan is one model that can be mix and match with various types of other clothes. In addition, with any style, cardigans will never be called outdated. It is also mentioned that cardigan is very appropriate to be used as supporting the appearance, especially if you have tired of wearing clothes that are always worn, then the look will be more fresh and stylist.

As mentioned above, that outer outfit has multifunctional, so it's better that every muslim woman needs to have it. Long cardigans are including the outer outfit of cardigan type but made long to exceed the knee. Long cardigans now, especially in Indonesia are made from various materials such as cotton, batik, brocade, chiffon, denim, t-shirt, spandek, knit, songket, woven etc. Some long cardigan functions are as follows: 1) With large and long form, this will disguise a fat woman, and 2) Can help women who want to dress syar'i muslim, because it can indirectly cover the aurat so it looks more comfortable . Long cardigans are usually made with various models, but the most common is the basic model, ie straight down from the top (www.hijabina.com).
Below we will show some models of long cardigans for formal, casual, and work opportunities that give the impression of style to the wearer:
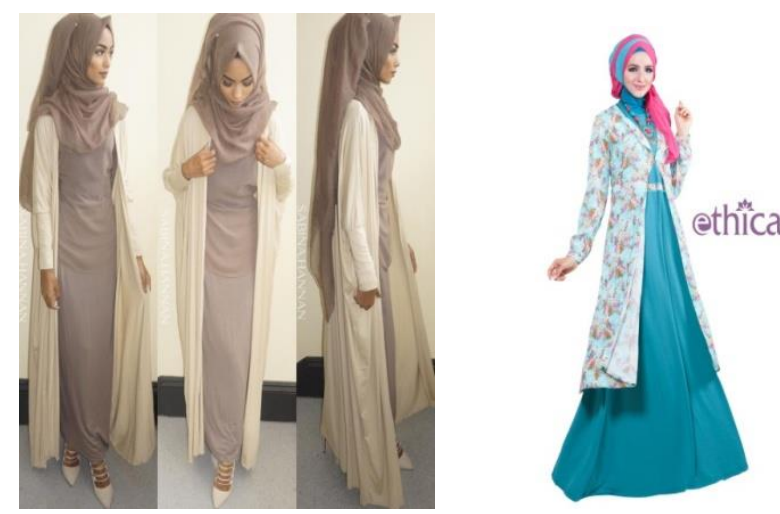

Fig. 7. Formal Long Cardigan

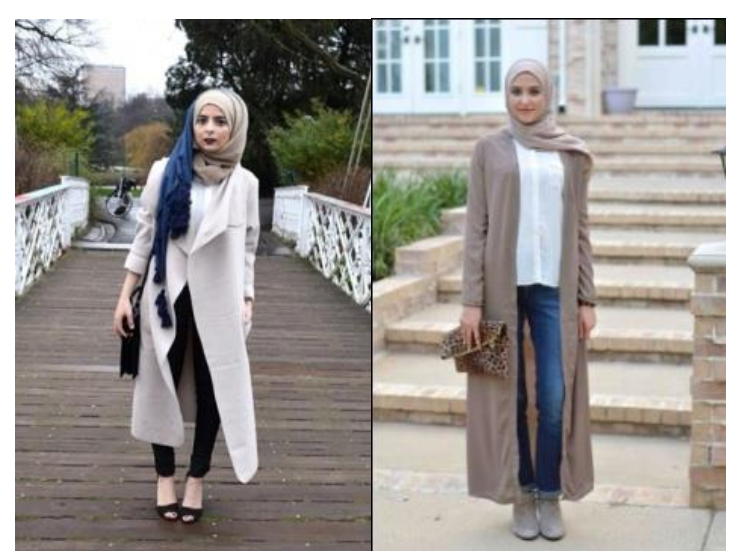

Fig. 8. Casual Long Cardigan
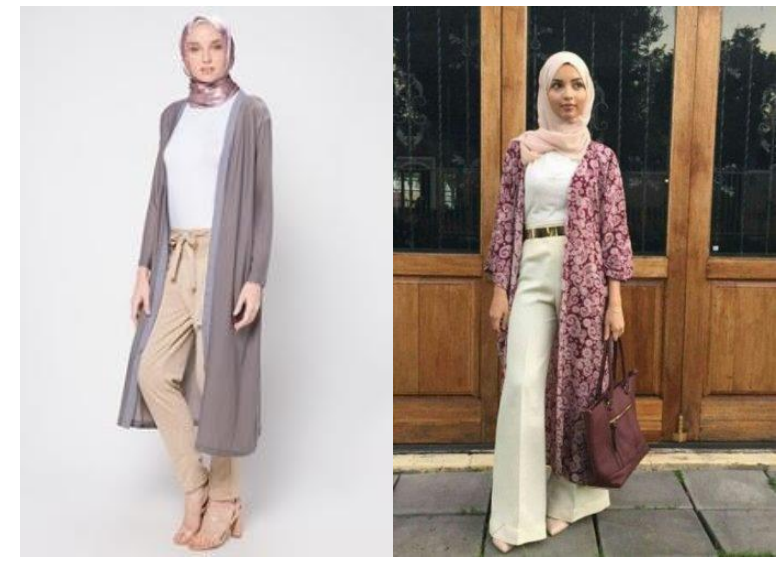

Fig.9 Office Long Cardigan 
To choose a long cardigan as a supporter of clothing, then there are some things to note: 1) To display a relaxed but formal atmosphere, it can use a plain long cardigan with a neutral color, 2) Long cardigan is very appropriate in use with jeans especially if jeans look very tight, using long cardigan can cover the body of the wearer, 3 ) If the long-sleeved tops, will look stylish when the arm cardigannya in roll, 4) Long cardigan can be combined with jumpsuit, 5) Long cardigan can be combined Also with maxi dress, 6) Long cardigan can be combined with a skirt, 7) The use of cardigans need to adjust to the season, when winter choose warm materials, and when summer heat select the material that is thin, light and absorb sweat, 8) Cardigan must be precise, if the clothing in patterned select plain cardigan, and if the dress in motifs can memili $\mathrm{H}$ patterned or plain cardigan, and 9) Color selection should be harmonious as well in the selection of shoes to be precise.

In addition, the use of cardigans should be adjusted also with the body shape of the wearer, for example: 1) For the obese, you should use a plain cardigan, the opposite when a skinny body can use patterned cardigans, 2) If you have a large pelvis and thighs, then Need to avoid the cardigan that fall in the widest part of the pelvis and thighs because it will give the impression of big plus, 3) If mimiliki wide shoulder aakan better choose cardigans from knitted material, 4) When have a large chest, then can choose cardigan with neck shaped V-shaped, And 5) For those who have a stomach crease, it can choose a cardigan that intersects straight at the waist and length covers the abdomen.

\section{CONCLUSION}

Based on the above description, it can be concluded that the outer has multifunction, including: 1) Can be used to warm the body, 2) Can grow self-confidence, 3) Is the most practical choice of clothing when wanting to show simple impression, 4) Outer mix And mach with clothing worn, the origin harmonious in the election, 5) Can be a choice of clothing style and look more fresh, 6) In order for outer more function in its use, then the main clothes should be smaller or not loose, and 7) aouter can be used for Various opportunities, formal, casual, and for work. .

\section{REFERENCES}

[1] Dictionary.com Unabridged, Based on the Random House Dictionary, (C Random House, Inc. 2017. https://en.wikipedia.org.Outerwear

[2] Deviantri,E. Variasi Gaya Cardigan Rok \& Dress. Jakarta: PT. Kawah Media,2014.

[3] Folkers,N. The Trench Book, www.assouline.com

[4] Kawabata, S.,Niwa,M.,Nakamo,K., and Inoue, T., "Fabric Hand Property of Polish Linen Fabrics for Ladies Outerwear," International Journal of Clothing Science Technology, vol. 12, pp. 193-204, 2010.

[5] Mari, S.A., Patrick,A., "Sociology of Fashion. International Encyclopedia of the Social Science," Elsevier Ltd, vol. 8, pp. 54115415, 2001.

[6] Yhulianayuli.blogspots.com. Karya Ilmiah Remaja: Trend Mode Para Remaja. Di akses 3 February 2014

[7] Shorter Oxford English Dictionary. Outerwear.

[8] https://www.merriam-webster.com/dictionary/outerwear

[9] www.hijabusanamuslim.com. 30 Model Outerwear Muslimah Yang Paling Trend Terbaru Tahun Ini. Di akses 6 Oktober 2017.

[10] Wikipedia.org

[11] Valentine, M.M, "Trend Mechanism in Contemporary Fashion," Design Issue, vol.29, Winter 2013. 